\title{
Research Paper: Incidence of Low Back Injuries Among Iranian Athletes in 12 Disciplines of Olympic Sports
}

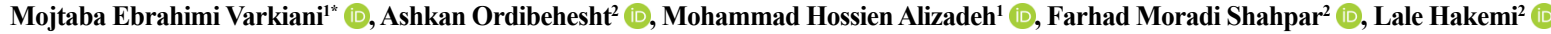 \\ 1. Department of Sports Injuries and Corrective Exercises, Faculty of Physical Education and Sports Sciences, University of Tehran, Tehran, Iran. \\ 2. Tehran Sport Medicine Federation, Tehran, Iran.
}

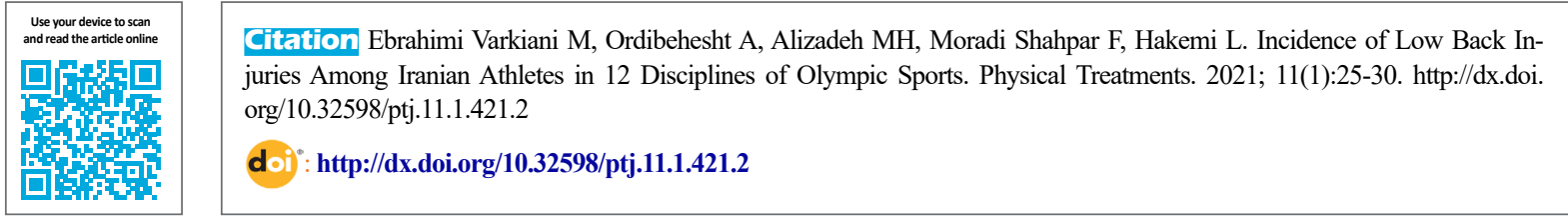

\section{(c) (i) (8)}

Article info:

Received: 23 Jun 2020

Accepted: 13 Oct 2020

Available Online: 01 Jan 2021

Keywords:

Low back pain, Incidence rate, Athlete, Lumbar spine, Injury surveillance system

\begin{abstract}
A B S T RA C T
Purpose: The present research aimed to determine the prevalence and incidence rate of low back pain and injury in 12 Olympic sports athletes presenting to the injury surveillance system of the Sports Medicine Federation of Iran.

Methods: A retrospective analysis was conducted on the data of athletes from the injury surveillance system of the Sports Medicine Federation of Iran, for three years. Descriptive statistic was used for the study.

Results: The incidence rate of 6.7 injuries per 10000 athletes registered was calculated for low back complaints in 12 sports disciplines. Weightlifting, wushu, and judo had the highest, and gymnastic and soccer had the lowest low back injuries incidence. More than one-third of the low back complaints involved the lumbar spine. Also, females were at higher risk of low back pain and injury than males. Of age categories, adults and elderlies had the highest prevalence of low back complaints with more involvement in the lumbar spine.

Conclusion: According to the results, wushu, judo, and especially weightlifting should be the priority of prevention. Furthermore, females and elderlies require more focus on preventive measures.
\end{abstract}

\section{* Corresponding Author:}

Mojtaba Ebrahimi Varkiani, PhD.

Address: Department of Sports Injuries and Corrective Exercises, Faculty of Physical Education and Sports Sciences, University of Tehran, Tehran, Iran Phone: +98 (912) 4318763

E-mail: m.ebrahimi@ut.ac.ir 


\section{Highlights}

- Weightlifting, wushu, and judo showed the highest low back injury incidences.

- More than one-third of the low back complaints involved the lumbar spine.

- Females were at higher risk of low back pain and injury than males.

\section{Plain Language Summary}

This study considered the low back injuries in athletes among 12 sport discipline. Weightlifting had highest rate of injury. More than one-third of the low back complaints involved the lumbar spine. Females were at higher risk of injury to ow back. adults and the elderly had the highest prevalence of low back complaints. Accordingly, wushu, judo, and especially weightlifting should be in priority of prevention.

\section{Introduction}

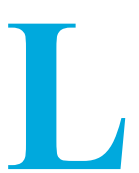

ow back pain is one of the most common health problems that creates a substantial personal, community, and financial burden globally [1]. The lifetime prevalence of low back pain is $85 \%$ to $90 \%$ in adults, also, $2 \%$ to $5 \%$ of people incur low back pain once a year [2]. A systematic review of 56 studies reported the prevalence ranges of $22 \%$ to $65 \%$ and $11 \%$ to $84 \%$ for the 1 -year and lifetime prevalence of low back pain, respectively [3]. Besides, the prevalence rate is increasingly rising each year. Freburger et al. reported a significant rise in chronic impairing low back pain over 14 years: from $3.9 \%$ in 1992 to $10.2 \%$ in 2006 [4]. This common complaint is also widespread in athletes. Different studies reported the prevalence of low back pain in different sport disciplines. The lifetime prevalence of low back pain in wrestlers was reported as $59 \%$, which was significantly higher than in the control group (31\%) [5]. Also, a higher rate of low back symptoms $(79 \%)$ was observed in elite gymnasts, compared with the control group (with the prevalence of $38 \%$ ) [6]. Likewise, Kujala et al. reported a low back pain rate of $46 \%$ among adolescent athletes, compared with $18 \%$ in nonathletes [7]. Additionally, Orchard et al. reported that footballers in Australia have significantly more severe and frequent low back pain than a nonathletic group [8].

Low back pain is not the same as a low back injury. Sometimes, the most common complaint (pain) may not result in a clinic-pathological diagnosis of a specified injury. Among a total number of 1108 injuries in the 2008 Summer Olympic Games, 78 injuries occurred in the lumbar spine, defining $7 \%$ of all injuries [9]. Besides, the lumbar spine incurred $6 \%$ of acute and $13 \%$ of chronic injuries in the African Olympic team [10]. Low back pain is a complaint in athletes and may force them to stop their activity for a short or long-time. Orchard et al. stated that in each season 5\% of Australian football players miss a match because of lumbar or thoracic spine injuries, causing them to miss four weeks/matches [8].

Nowadays, the importance of the athletes' health issues is increasing, also, large investments are being made in sports-related fields. Therefore, each day's absence of the athlete may impose a huge cost on the sport clubs and sponsors. Treatment costs add additional charges to the clubs, athletes, and insurance organizations. Thus, prevention gets into priority and importance. According to the Van Mechelen injury prevention model, 1992, the magnitude of the problem should first be recognized with the epidemiological studies to be able to plan a preventive measure. Hence, establishing the range of the sport low back pain and injury is the first step of prevention. Accordingly, the present research aimed to study the prevalence and incidence rate of low back pain and injury in 12 Olympic sports athletes presenting to the injury surveillance system of the Sports Medicine Federation of Iran.

\section{Materials and Methods}

\section{Participants}

A retrospective analysis was conducted on the data of athletes from the injury surveillance system of the Sport Medicine Federation of Iran, for two years of the Persian calendar, from March 21, 2009 to March 20, 2011. The studied sports included soccer, volleyball, handball, basketball, taekwondo, wushu, judo, karate, gymnastic, weightlifting, boxing, and wrestling. Also, the age and sex categories were considered. 


\section{Procedure}

This was a descriptive study, where the injury surveillance system of the sport medicine federation was operated to provide sport-related injuries incurred by insured athletes participating in various sports from all provinces of the country. All insured athletes injured should present to the sport medicine federation to be referred to the hospital or clinic for treatment. In the present study, the injury was defined as any reported event to the injury surveillance system of the sport medicine federation, considering the following conditions: the injury was resulted from participating in competition or practice, required medical attention by a physician, and restricted the athlete's participation for at least one day beyond the injury.

\section{Statistical analysis}

Descriptive statistic was used for the study analysis. All statistical analysis was done by SPSS V. 14. Besides, injury rates were calculated from the reported injuries of registered athletes, using the basic rate formula: (\#injuries/\# athletes registered) $\times 10000=\#$ injuries per 10000 athletes registered. The incidence rate was reported according to the registered athletes, also, the method has been used for incidence rate calculation in the Olympic Games [9].

\section{Results}

Out of 37046 injured athletes (Mean \pm SD age= $25.62 \pm 6.38$; rang $=7-60$ years) presented to the injury surveillance system over two, 967 had the low back and lumbar spine complaints. Table 1 provides the sport injuries distribution. As presented, females had a higher risk of low back pain and injury, compared with males. Likewise, the prevalence was higher in adults and elderlies aged 44 to 60 years, compared with other age groups (Table 2). The frequency percent of lumbar spine injuries was lower than that of non-spinal ones in all age categories except adults and elderlies aged 44 to 60 years (3.3\% vs $2.4 \%$ ).

\section{Discussion}

This research aimed to determine the prevalence and incidence of low back pain and injury in 12 Olympic sports athletes presenting to the injury surveillance system of the Sports Medicine Federation of Iran. The incidence rate was calculated to be 6.7 injuries per 10000 athletes. Thus, low back pain and injuries established $2.6 \%$

Table 1. Incidence rate of low back injuries in 12 sports disciplines (per 10000 athletes registered)

\begin{tabular}{|c|c|c|c|c|c|c|c|c|c|}
\hline \multirow[b]{2}{*}{ Sport } & \multicolumn{2}{|c|}{ All Body Parts } & \multicolumn{2}{|c|}{ Low Back } & \multicolumn{2}{|c|}{ Lumbar Spine } & \multicolumn{3}{|c|}{ Total } \\
\hline & $\begin{array}{l}\text { Number of } \\
\text { Athletes } \\
\text { Registered }\end{array}$ & $\begin{array}{l}\text { Number of } \\
\text { All Injuries }\end{array}$ & $\begin{array}{l}\text { Number of } \\
\text { Injuries }\end{array}$ & $\begin{array}{l}\text { Percent (to } \\
\text { All Injuries) }\end{array}$ & $\begin{array}{l}\text { Number of } \\
\text { Injuries }\end{array}$ & $\begin{array}{l}\text { Percent (to } \\
\text { All Injuries) }\end{array}$ & $\begin{array}{l}\text { Number of } \\
\text { Injuries }\end{array}$ & $\begin{array}{l}\text { Percent (to } \\
\text { All Injuries) }\end{array}$ & $\begin{array}{l}\text { Ratio (Injury Per } \\
10000 \text { Athletes } \\
\text { Registered) }\end{array}$ \\
\hline Soccer & 584444 & 15325 & 154 & $1 \%$ & 109 & $0.7 \%$ & 263 & $1.7 \%$ & 4.5 \\
\hline Volleyball & 110256 & 2150 & 56 & $2.6 \%$ & 30 & $1.4 \%$ & 86 & $4 \%$ & 7.8 \\
\hline Handball & 19117 & 829 & 16 & $1.9 \%$ & 10 & $1.2 \%$ & 26 & $3.1 \%$ & 13.6 \\
\hline Basketball & 65789 & 1560 & 32 & $2.1 \%$ & 18 & $1.2 \%$ & 50 & $3.3 \%$ & 7.6 \\
\hline Taekwondo & 165217 & 4379 & 69 & $1.6 \%$ & 45 & $1 \%$ & 114 & $2.6 \%$ & 6.9 \\
\hline Wushu & 42937 & 1840 & 47 & $2.6 \%$ & 29 & $1.6 \%$ & 76 & $4.2 \%$ & 17.7 \\
\hline Judo & 26553 & 1323 & 32 & $2.4 \%$ & 15 & $1.1 \%$ & 47 & $3.5 \%$ & 17.7 \\
\hline Karate & 144067 & 2876 & 60 & $2.1 \%$ & 25 & $0.9 \%$ & 85 & $3 \%$ & 5.9 \\
\hline Gymnastic & 144444 & 1179 & 25 & $2.1 \%$ & 14 & $1.2 \%$ & 39 & $3.3 \%$ & 2.7 \\
\hline Weightlifting & 5015 & 268 & 28 & $10.4 \%$ & 5 & $1.9 \%$ & 33 & $12.3 \%$ & 65.8 \\
\hline Boxing & 16528 & 984 & 11 & $1.1 \%$ & 9 & $0.9 \%$ & 20 & $2 \%$ & 12.1 \\
\hline Wrestling & 98461 & 4333 & 75 & $1.7 \%$ & 53 & $1.2 \%$ & 128 & $2.9 \%$ & 13.0 \\
\hline Total & 1422828 & 37046 & 605 & $1.6 \%$ & 362 & $1 \%$ & 967 & $2.6 \%$ & 6.7 \\
\hline
\end{tabular}

a Sports with a higher injury rate are bolded. 
Table 2. Descriptive analysis of low back pain and injury categorized by sex and age

\begin{tabular}{|c|c|c|c|c|c|c|c|c|c|c|}
\hline \multirow{2}{*}{\multicolumn{2}{|c|}{ Factor }} & \multicolumn{2}{|c|}{ All Body Parts } & \multicolumn{2}{|c|}{ Low Back } & \multicolumn{2}{|c|}{ Lumbar Spine } & \multicolumn{3}{|c|}{ Totala } \\
\hline & & $\begin{array}{l}\text { Number of } \\
\text { Athletes } \\
\text { Registered }\end{array}$ & $\begin{array}{l}\text { Number of } \\
\text { All Injuries }\end{array}$ & $\begin{array}{l}\text { Number } \\
\text { of Injuries }\end{array}$ & $\begin{array}{l}\text { Percent (to All } \\
\text { Injuries) }\end{array}$ & $\begin{array}{l}\text { Number of } \\
\text { Injuries }\end{array}$ & $\begin{array}{l}\text { Percent (to All } \\
\text { Injuries) }\end{array}$ & $\begin{array}{l}\text { Number } \\
\text { of Injuries }\end{array}$ & $\begin{array}{l}\text { Percent (to } \\
\text { All Injuries) }\end{array}$ & $\begin{array}{c}\text { Ratio (Injury Per } \\
10000 \text { Athletes } \\
\text { Registered) }\end{array}$ \\
\hline \multirow{3}{*}{ Sex } & Male & 1164330 & 32314 & 490 & $1.5 \%$ & 280 & $0.9 \%$ & 770 & $2.4 \%$ & 6.6 \\
\hline & & & & & & & & & & \\
\hline & Female & 258498 & 4732 & 115 & $2.4 \%$ & 82 & $1.7 \%$ & 197 & $4.1 \%$ & 7.6 \\
\hline \multirow{5}{*}{$\begin{array}{l}\text { Age } \\
\text { (y) }\end{array}$} & $7-14$ & & 5817 & 69 & $1.2 \%$ & 29 & $0.5 \%$ & 98 & $1.7 \%$ & \\
\hline & $15-24$ & & 18111 & 306 & $1.7 \%$ & 183 & $1 \%$ & 489 & $2.7 \%$ & \\
\hline & $25-44$ & & 8648 & 159 & $1.8 \%$ & 92 & $1.1 \%$ & 251 & $2.9 \%$ & \\
\hline & $45-60$ & & 545 & 13 & $2.4 \%$ & 18 & $3.3 \%$ & 31 & $5.7 \%$ & \\
\hline & Missing & & 3925 & & & & & & & \\
\hline
\end{tabular}

Higher injury rates and percents are bolded.

PHYSICAL TREA $\$ MENTS

of all injuries accrued in 12 sports disciplines and were lower than the rate reported for the United States community (1.39 per 1000 person-years) [11]. Farahbakhsh et al. reported a wide range of low back pain in athletes, ranging from $10 \%$ to $67 \%$ [12]. The low back pain and injury incidences of weightlifting $(65.8 / 10000)$, wushu (17.7/10000), judo (17.7/10000), handball (13.6/10000), wrestling (12.1/10000), and boxing (13/10000) were higher than those of the other sports disciplines. These sports are of high risk of low back injuries and the involved athletes may expose more to low back injuries.

Weightlifting was one of the sports with the highest injury rate in Iran and was not limited to the low back problems (Figure 1) [13]. The incidence of low back pain is correlated with higher lifting strength requirements [14]. Furthermore, it was reported that working with the trunk in bent and twisted positions for more than

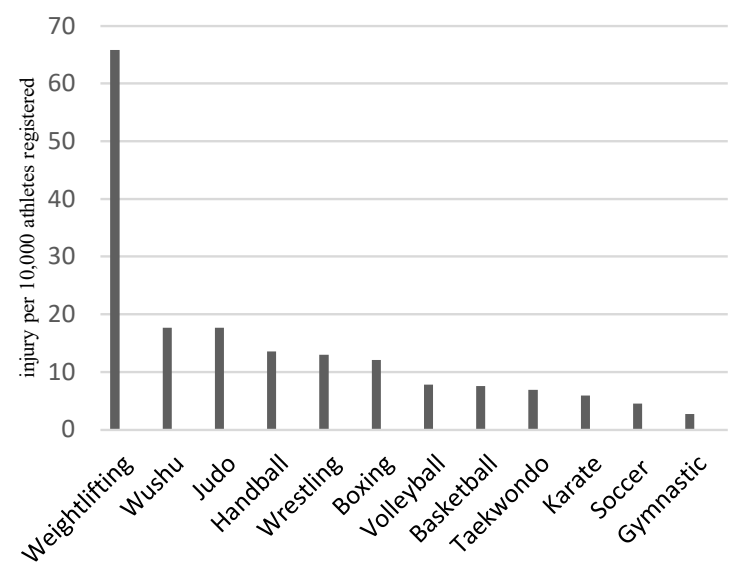

Figure 1. Incidence of low back pain and injury two hours/day may expose the athlete to a low back injury and should be considered as a risk factor for low back pain. Also, excessive weights puts the back in a compromising position that may lead to injury $[15,16]$. Moreover, Coenen et al. determined that the cumulative low back loads may be a significant risk factor for low back pain [17]. Compression loads may also cause injury to the intervertebral disk, the ring apophysis, and the endplate. In a systematic review, Heneweer et al. concluded that heavy workload and the accumulation of loads or the frequency of lifts were moderate to strong risk factors for low back pain [18]. Also, Fares et al. reported performing improper techniques as a risk factor for low back injuries [16]. While irreversible changes in the lumbar vertebra without symptoms were reported in children and adolescents undergoing resistance training [19]. Therefore, weightlifting is accumulated with most of the abovementioned risk factors, because of the high load pressure and frequent flexion/extension movements. On the other hand, the everyday training of weightlifters may expose them to low back injuries. Thus, weightlifting could be named as a sport discipline with the highest risk of low back injuries, as it was in the present study.

After weightlifting, martial arts like wushu and judo had a higher prevalence of low back injuries. Yabe et al. showed that judo players were exposed to more low back injuries in martial arts [20]. Moreover, 90\% of nonspecific low back pain is common in judokas with a reported prevalence between $35 \%$ and $62 \%$ [21, 22]. It may be due in part to twisting movements and lifting the opponents in competition and practice.

The exercise of each sport discipline may cause low back injury due to many risk factors. As the sport ac- 
tivities are performed with high intensity, the majority of body structures may expose to the risk of injury. Low back and lumbar spine are at higher risk because they are located at the center of the body and involved in all movements during athletic performance. Some movement patterns in sports may cause an injury to low back. Flexion and extension compression loads damage the intervertebral disk, the ring apophysis, and the endplate. Also, rotation compression loads have the same impact. Besides, the rotation of the lumbar spine involves the torsion of the intervertebral disks and the impact of the facet joints. Heavy loads expose low back to injury in wrestling, where forceful bending movements are exerted at high speed [23]. Hitting the blocking sled from a crouched position in football players, and lumbar extension while performing walkovers by gymnasts are common mechanisms associated with low back complaints [24].

It was shown that more than one-third of the low back complaints were incurred in the lumbar spine. It may force the athletes to stop participating in sport events. More investigation is required to find out the causes and mechanisms of low back complaints. Additionally, providing preventive measures seems to be necessary.

Consistent with previous studies [25, 26], females showed a higher incidence of low back injuries than males (7.6 vs 6.6 per 10000 athletes registered). As Wijnhoven et al. reported, women have a higher prevalence of musculoskeletal pain in most anatomic pain sites [27]. Furthermore, as females' flexibility and joint laxity are more than males, they may also be at a greater risk of spine injuries, such as disk degeneration, spondylolysis, and facet joint syndrome [23]. Thus, females are at higher risk of low back injuries than males.

Furthermore, the highest prevalence percent of low back complaints was observed in adults and elderlies aged 44 to 60 years (5.7\%); it was consistent with Beerman et al. [28]. The more important issue in the elderly is the higher frequency of lumbar spine injuries, compared with non-spinal injuries (3.3\% vs $2.4 \%$ ), which may be a threat to their lives and activities. In a systematic review by Dionne et al. a line trend showed that low back pain prevalence increases from 21 to 60 years of age, then, it decreases till 90 years of age, but the severe back pain continues to increase with age [29]. Additionally, it has been reported that the risk of incurring low back pain increases by $19 \%$ for every 5 -year increase in age [23].

\section{Conclusion}

The incidence rate of 6.7 injuries per 10000 athletes registered was calculated for low back complaints in 12 sports disciplines. Weightlifting, wushu, and judo had the highest, and gymnastic and soccer had the lowest low back injuries incidences. More than one-third of the low back complaints involved the lumbar spine. Females were at higher risk of low back pain and injury than males. Of age categories, adults and the elderly had the highest prevalence of low back complaints with more involvement in the lumbar spine. Accordingly, wushu, judo, and especially weightlifting should be in priority of prevention. Furthermore, females and the elderly require more focus on preventive measures.

\section{Ethical Considerations}

\section{Compliance with ethical guidelines}

All ethical principles are considered in this article. The data obtained by permission of Sport Medicine Federation

\section{Funding}

This research did not receive any grant from funding agencies in the public, commercial, or non-profit sectors.

\section{Authors' contributions}

All authors contributed equally in preparing all parts of the research.

\section{Conflict of interest}

The authors declared no conflict of interest

\section{Acknowledgments}

We appreciate the Sports Medicine Federation of Iran for cooperation and help.

\section{References}

[1] Hoy D, Bain C, Williams G, March L, Brooks P, Blyth F, et al. A systematic review of the global prevalence of low back pain. Arthritis \& Rheumatism. 2012; 64(6):2028-37. [DOI:10.1002/art.34347] [PMID]

[2] Bono CM. Low-back pain in athletes. The Journal of Bone \& Joint Surgery. 2004; 86(2):382-96. [DOI:10.2106/00004623200402000-00027] [PMID] 
[3] Walker BF. The prevalence of low back pain: A systematic review of the literature from 1966 to 1998. Journal of Spinal Disorders \& Techniques. 2000; 13(3):205-17. [DOI:10.1097/00002517-200006000-00003] [PMID]

[4] Freburger JK, Holmes GM, Agans RP, et al. The rising prevalence of chronic low back pain. Archives of Internal Medicine. 2009; 169(3):251-8. [DOI:10.1001/archinternmed.2008.543] [PMID] [PMCID]

[5] Granhed H, Morelli B. Low back pain among retired wrestlers and heavyweight lifters. The American Journal of Sports Medicine. 1988; 16(5):530-3. [DOI:10.1177/0363546588016005 17] [PMID]

[6] Swärd L, Hellström M, Jacobsson B, Nyman R, Peterson L. Disc degeneration and associated abnormalities of the spine in elite gymnasts: A magnetic resonance imaging study. Spine. 1991; 16(4):437-43. [DOI:10.1097/00007632-19910400000009] [PMID]

[7] Kujala UM, Taimela S, Erkintalo M, Salminen JJ, Kaprio J. Low-back pain in adolescent athletes. Medicine and Science in Sports and Exercise. 1996; 28(2):165-70. [DOI:10.1097/00005768-199602000-00002] [PMID]

[8] Orchard J, Seward H. Epidemiology of injuries in the Australian Football League, seasons 1997-2000. British Journal of Sports Medicine. 2002; 36(1):39-44. [DOI:10.1136/ bjsm.36.1.39] [PMID] [PMCID]

[9] Junge A, Engebretsen L, Mountjoy ML, Alonso JM, Renström PA, Aubry MJ, et al. Sports injuries during the Summer Olympic Games 2008. American Journal of Sports Medicine. 2009; 37(11):2165-72. [DOI:10.1177/0363546509339357] [PMID]

[10] Derman W. Medical care of the South African Olympic team: The Sydney 2000 experience. South African Journal of Sports Medicine. 2003; 15(3):22-5. [DOI:10.17159/2078-516X/2003/ v15i3a224]

[11] Waterman BR, Belmont Jr PJ, Schoenfeld AJ. Low back pain in the United States: incidence and risk factors for presentation in the emergency setting. The Spine Journal. 2012; 12(1):63-70. [DOI:10.1016/j.spinee.2011.09.002] [PMID]

[12] Farahbakhsh F, Rostami M, Noormohammadpour P, Mehraki Zade A, Hassanmirazaei B, Faghih Jouibari M, et al. Prevalence of low back pain among athletes: A systematic review. Journal of Back and Musculoskeletal Rehabilitation. 2018 31(5):901-16. [DOI:10.3233/BMR-170941] [PMID]

[13] Ebrahimi Varkiani M, Alizadeh MH, Pourkazemi L. [Epidemiology of sport injuries of Iran's athletes via IRI sport medicine federation database: 21 sports in 2009-2011 (Persian)] [MSc. thesis]. Tehran: University of Tehran; 2013.

[14] Chaffin DB, Park KS. A longitudinal study of low-back pain as associated with occupational weight lifting factors. American Industrial Hygiene Association Journal. 1973; 34(12):51325. [DOI:10.1080/0002889738506892] [PMID]

[15] Van Nieuwenhuyse A, Somville P-R, Crombez G, Burdorf A, Verbeke G, Johannik K, et al. The role of physical workload and pain related fear in the development of low back pain in young workers: Evidence from the BelCoBack Study: Results after one year of follow up. Occupational and Environmental Medicine. 2006; 63(1):45-52. [DOI:10.1136/oem.2004.015693] [PMID] [PMCID]
[16] Fares MY, Fares J, Salhab HA, Khachfe HH, Bdeir A, Fares Y Low back pain among weightlifting adolescents and young adults. Cureus. 2020; 12(7):e9127. [DOI:10.7759/cureus.9127]

[17] Coenen P, Kingma I, Boot CR, Twisk JW, Bongers PM, van Dieën JH. Cumulative low back load at work as a risk factor of low back pain: A prospective cohort study. Journal of Occupational Rehabilitation. 2013; 23(1):11-8. [DOI:10.1007/ s10926-012-9375-z] [PMID] [PMCID]

[18] Heneweer H, Staes F, Aufdemkampe G, Rijn M, Vanhees L. Physical activity and low back pain: A systematic review of recent literature. European Spine Journal. 2011; 20(6):826-45. [DOI:10.1007/s00586-010-1680-7] [PMID] [PMCID]

[19] Shimozaki K, Nakase J, Yoshioka K, Takata Y, Asai K, Kitaoka $\mathrm{K}$, et al. Incidence rates and characteristics of abnormal lumbar findings and low back pain in child and adolescent weightlifter: A prospective three-year cohort study. PLoS ONE. 2018; 13(10):e0206125. [DOI:10.1371/journal. pone.0206125] [PMID] [PMCID]

[20] Yabe Y, Hagiwara Y, Sekiguchi T, Momma H, Tsuchiya M, Kanazawa K, et al. Low back pain in school-aged Martial arts athletes in Japan: A comparison among Judo, Kendo, and Karate. The Tohoku Journal of Experimental Medicine. 2020; 251(4):295-301. [DOI:10.1620/tjem.251.295] [PMID]

[21] Maher C, Underwood M, Buchbinder R. Non-specific low back pain. The Lancet. 2017; 389(10070):736-47. [DOI:10.1016/ S0140-6736(16)30970-9]

[22] Triki M, Koubaa A, Masmoudi L, Fellmann N, Tabka Z Prevalence and risk factors of low back pain among undergraduate students of a sports and physical education institute in Tunisia. Libyan Journal of Medicine. 2015; 10:26802. [DOI:10.3402/ljm.v10.26802] [PMID] [PMCID]

[23] Bahr R, Engebretsen L. Sports injury prevention. Oxford: Blackwell Publishing; 2009. [DOI:10.1002/9781444303612]

[24] Hutchinson MR. Low back pain in elite rhythmic gymnasts. Medicine and Science in Sports and Exercise. 1999; 31(11):1686-8. [DOI:10.1097/00005768-199911000-00027] [PMID]

[25] Leboeuf-Yde C, Kyvik KO. At what age does low back pain become a common problem? A study of 29,424 in dividuals aged 12-41 years. Spine. 1998; 23(2):228-34. [DOI:10.1097/00007632-199801150-00015] [PMID]

[26] Grimmer K, Williams M. Gender-age environmental associates of adolescent low back pain. Applied Ergonomics. 2000; 31(4):343-60. [DOI:10.1016/S0003-6870(00)00002-8]

[27] Wijnhoven HAH, de Vet HCW, Picavet HSJ. Prevalence of musculoskeletal disorders is systematically higher in women than in men. The Clinical Journal of Pain. 2006; 22(8):717-24. [DOI:10.1097/01.ajp.0000210912.95664.53] [PMID]

[28] Beermann LE, Wasserman EB, Williams RM, Simon JE, Dompier TP, Kerr ZY, et al. Epidemiology of low back injuries sustained by secondary school athletes: A report from the national athletic treatment, injury, and outcomes network Journal of Athletic Training. 2017; 52(6):S181-S182. https:/ / search.proquest.com/openview/158eeabb6ad7591d7d6fd6a 5 f84bb53b/1?pq-origsite $=$ gscholar\&cbl $=47878$

[29] Dionne CE, Dunn KM, Croft PR. Does back pain prevalence really decrease with increasing age? A systematic review. Age and Ageing. 2006; 35(3):229-34. [DOI:10.1093/ageing/afj055] [PMID] 